\title{
Derechos Humanos Y Trabajo Infantil En El Estado De Hidalgo
}

\section{RESUMEN}

Azul Valdivieso Martínez *

El objetivo de este artículo ${ }^{1}$ es analizar la situación de los derechos humanos y el trabajo infantil de los Jornaleros Agrícolas Migrantes (JAM) en el Valle del Mezquital, Hidalgo.

\section{ABSTRACT}

The objective of this article is to analyze the human rights situation and child labour of the migratory agricultural worker, in the Valle of Mezquital, Hidalgo.

\section{* Maestra en Educación por la Universidad Autónoma del Estado de Hidalgo, profesora investigadora en la misma Universidad. azulgvm@yahoo.es}

El tema de la migración interna en México, ha sido poco abordado en el campo de la migración; la tendencia de los diversos estudios, está más orientada a la situación internacional (principalmente de nuestra frontera con Estados Unidos), y menos a los movimientos migratorios internos y sus implicaciones, por lo que en diversos foros nacionales, se aborda la problemática como "La Invisibilidad de los Jornaleros Agrícolas Migrantes", lo que alude a la realidad de su existencia (desconocida), a la necesidad de atención pronta por la vulnerabilidad en la que se encuentran y, a la urgencia de políticas sociales integrales y sensibles dirigidas a apoyar y proteger los derechos humanos de este grupo social.

El problema de los derechos humanos ${ }^{2}$ de los jornaleros agrícolas migrantes, se presenta como uno de los asuntos más importantes a atender en este grupo social, ya que, como a continuación se detallará, las condiciones de educabilidad (materiales, culturales y sociales) de los niños y niñas que pertenecen a familias de Jornaleros Agrícolas Migrantes (JAM), son desfavorables e impiden aprovechar plenamente las garantías fundamentales a las que, según las leyes de nuestro país, tienen derecho y que el Estado Mexicano, a pesar de diversos programas dirigidos a esta población no ha logrado garantizar.

\section{Situación de los jornaleros agrícolas migrantes}

Los estudios sobre migración identifican varios tipos de emigrantes. En el caso de la migración interna que nos ocupa, se distingue entre los emigrantes "golondrina" y "emigrantes circulares, de retorno, o pendulares". Los primeros se refieren al desplazamiento de un lugar a otro del territorio sin regresar a su lugar de origen, pues, en muchos casos, no cuentan siquiera con un lugar fijo de residencia; los segundos se desplazan por razones laborales a uno o varios lugares dentro del territorio nacional, pero regresan siempre a su lugar de origen donde, por lo general, tienen su domicilio permanente. 
De acuerdo con el Programa de Atención a Jornaleros Agrícolas (PAJA), programa de la Secretaría de Desarrollo Social (SEDESOL), los jornaleros agrícolas:

...se clasifican en migrantes y locales. Entre los primeros se encuentran los pendulares, quienes salen periódicamente de sus lugares de origen durante lapsos de 4 a 6 meses y que, al término de la temporada agrícola, regresan a sus comunidades, y los jornaleros migrantes golondrinos, quienes recorren diversas zonas de trabajo durante todo el año, enlazando empleos en diferentes tipos de cultivo (PAJA, 2005: 1).

Cualquiera que sea el modelo de migración que ejerce una persona o un grupo, ésta puede suceder a nivel regional, nacional e internacional. Recientemente se agrega a éstas formas tradicionales de migración un nuevo modelo de "transmigración" ${ }^{3}$, el cual ya no sigue necesariamente la lógica de migrar para sobrevivir, sino de "vivir migrando". Como describe Pries (2002:571):

en este caso, la migración ya no es un evento singular, transitorio y excepcional en la vida, sino que se convierte por sí misma en una forma de existir, de vivir y sobrevivir.

Las redes sociales que se han construido, y que constituyen la forma de vida de esta población, muestra que llegan a los municipios de Mixquiahuala y Progreso de Obregón, Hidalgo, a trabajar jornaleros agrícolas que provienen, en lo fundamental, de los estados de Guerrero y Morelos. Entre los meses de marzo y abril arriban a estos municipios del Valle del Mezquital y en octubre regresan a sus pueblos de origen, en marzo del año siguiente repiten el ciclo, por lo que adoptan un claro patrón de migración pendular.

Los jornaleros que llegan al Valle del Mezquital pertenecen a tres grupos étnicos principales: nahuatls, mixtecos y tlapanecos y llegan a la zona a trabajar en la pizca del ejote, en terrenos de pequeños y medianos productores de los ejidos que cuentan con riego.

A diferencia de otras formas de migración por razones laborales, en este caso no viajan los jornaleros en forma individual, sino que se desplazan familias completas, incluyendo ancianos y niños pequeños. En 2005 llegaron a la zona 767 personas que pertenecen a 138 familias. Éstas se alojaron en tres campamentos y en dos albergues construidos por el Gobierno del Estado de Hidalgo.

Debido al patrón migratorio adoptado por estas familias, surge un nuevo tipo de estudiante, que por lo general no se contempla en los esquemas educativos tradicionales y no puede ser atendido por los programas regulares: el estudiante migratorio. En este sentido es oportuno recuperar la definición que sobre este tipo de estudiantes emplean investigadores de la migración interna en Estados Unidos:

Un estudiante migratorio es un niño cuyo padre o encargado es un trabajador agrícola migratorio o un pescador que viaja de un distrito o 
un área administrativa escolar a otra durante el periodo lectivo regular. El niño puede haber interrumpido su educación como resultado de este traslado, el cual se hace para que el niño, su encargado, o un miembro de su familia inmediata obtengan un empleo temporal o estacional en actividades agrícolas o de pesca (Lunon, 1988).

En muchos países existe este tipo de estudiantes migratorios y los gobiernos han diseñado programas especiales para atender a esta población.

En el caso de estudio encontramos a menores que viajan con sus familias para trabajar como jornalero agrícola o para acompañar a sus padres y hermanos que laboran como tales, para ello se trasladan de un estado a otro e interrumpen la asistencia a la escuela o en ocasiones no ingresan a la educación básica. Ante este problema el Gobierno Federal ha diseñado programas especiales para atender a esta población. En el caso de Hidalgo, en cada campamento y albergue, se dan servicios educativos a grupos de entre 35 y 40 estudiantes; en 2005 se atendió a una población de 193 alumnos en los niveles preescolar y primaria, bajo un esquema de organización multigrado.

El problema básico es que, a pesar de las acciones realizadas a través Programa de Educación Básica para Niñas y Niños Migrantes (PRONIM) de la SEP, que dota a campamentos y albergues de aulas, maestros y material didáctico; diseña un modelo educativo adaptado a los inmigrantes, establece un calendario escolar que se ajusta al ciclo agrícola y a los movimientos migratorios y establece un horario de clases que considera las necesidades de los niños jornaleros. Éstos por lo general no asisten a la escuela o lo hacen en forma muy irregular, lo que dificulta el aprovechamiento escolar y la permanencia de los estudiantes migratorios en el sistema de enseñanza, como lo muestran los pobres resultados en cuanto a eficiencia terminal y asiduidad que tienen los estudiantes migratorios.

En este sentido, es posible afirmar que el estado, por medio del PRONIM, ha realizado las acciones educativas deseables para adaptarse a las condiciones particulares de los niños migratorios. Pero, a pesar de ello, los estudiantes no logran terminar la primaria ni contar con las competencias que trata de desarrollar en los alumnos la educación básica.

\section{Condiciones de educabilidad materiales de los JAM}

De acuerdo con Néstor López y Juan Carlos Tedesco, por condiciones de educabilidad, puede entenderse que:

Apunta a identificar cuál es el conjunto de recursos, aptitudes o predisposiciones que hacen posible que un niño o adolescente pueda asistir exitosamente a la escuela, al mismo tiempo que invita a analizar cuáles son las condiciones sociales que hacen posible que todos los niños y adolescentes accedan a esos recursos (López y Tedesco,2002:7). 
De forma similar Manuel Bello define el concepto de la siguiente forma:

La educabilidad, en el sentido que se adopta en este estudio, alude al grado o nivel de desarrollo en cada individuo de características biológicas y personales que afectan su capacidad para beneficiarse en mayor o menor medida de las oportunidades de aprendizaje que le brinda la escuela. La ausencia de un mínimo de equidad social vulnera las condiciones de educabilidad de las poblaciones excluidas o discriminadas. (Bello, 2003:1).

Existe, entonces, un conjunto de procesos en el contexto en que vive y estudia un alumno, que influye en las oportunidades de éxito escolar y aprovechamiento de las posibilidades educativas que existen en una sociedad, entendiendo por "éxito" el solo hecho de ingresar, asistir a clases y culminar los estudios, con independencia de que se tengan o no calificaciones sobresalientes. Llamaremos "condiciones sociales de educabilidad" a este conjunto de particularidades del contexto social del estudiante. Hay tres grandes grupos de condiciones que se consideran relevantes: materiales, culturales y sociales, las cuales a su vez se descomponen en indicadores más específicos. Para el análisis que se pretende en este artículo, sólo se abordarán las condiciones de educabilidad materiales de los JAM.

\section{Condiciones de educabilidad materiales}

Las familias migrantes que llegan a trabajar al estado de Hidalgo son campesinos sin tierra, indígenas pobres que viajan a trabajar como jornaleros, debido a la falta de oportunidades de trabajo en sus lugares de origen (Guerrero y Morelos, principalmente). En algunos casos la ganancia obtenida al migrar a Hidalgo será el único ingreso que tendrán en todo el año. Lo que perciben cuando viajan al Valle del Mezquital lo complementan con el ingreso que obtienen como jornaleros agrícolas en su lugar de origen o en otras partes del país, o con lo que reciben otros miembros del hogar que laboran en diversas actividades.

Las familias estudiadas constituyen unidades de producción y consumo que adoptan estrategias de sobrevivencia, en las cuales los distintos miembros aportan recursos realizando actividades que se pueden desarrollar en diversos lugares del país o del extranjero, a pesar de dicha dispersión geográfica, todos los integrantes del hogar responden a una misma lógica, esto es, los movimientos migratorios que efectúan no dependen sólo de sus preferencias o gustos particulares, sino principalmente de las estrategias de sobrevivencia adoptadas por la familia.

Los jornaleros trabajan a destajo, reciben un ingreso que oscila entre $\$ 0,80$ y $\$ 1,00$ por kilo de ejote cortado. Cada familia corta a la semana entre 400 y 2000 kilos, dependiendo del número de integrantes, lo que significa que las familias tienen un ingreso mensual familiar de entre $\$ 1600$ y $\$ 8000$; cuando dividimos estos ingresos entre el número de integrantes de la familia se obtiene el ingreso 
mensual per cápita, indicador que permite a su vez observar la posición de las familias con respecto a distintas líneas de pobreza.

Como puede apreciarse, siete de cada 10 hogares experimenta diversos niveles de pobreza y una tercera parte de las familias puede considerarse que vive en condiciones de pobreza extrema. El bajo nivel socioeconómico de las familias se expresa, además, en la existencia de necesidades sociales y económicas básicas insatisfechas y, en particular, en las malas condiciones materiales de la vivienda, tanto en sus lugares de origen como en los campamentos y albergues en los que permanecen cuando trabajan en el estado de Hidalgo, lo que dificulta que los menores cuenten en sus casas con comodidades mínimas para estudiar y hacer las tareas escolares.

Otro indicador específico de las condiciones de educabilidad materiales, es la importancia del trabajo infantil, como una estrategia de sobrevivencia. Los bajos ingresos que obtienen las familias, hacen que éstas requieran del trabajo de todos los miembros, aún los niños en edad escolar. No existe consenso sobre los motivos que impulsan a las familias a llevar a sus hijos a la pizca del ejote, aún cuando eso significa que no asistan a la escuela o lo hagan de una forma muy irregular. En el caso estudiado se identificaron al menos tres tipos de factores:

a) El significado cultural de trabajo; los jornaleros consideran que los niños no sólo aprenden en la escuela sino también en el trabajo. No piensan que emplear a los niños sean un tipo de explotación, sino una forma de preparación para la vida. Para las familias de jornaleros migrantes, el trabajo de los niños no se percibe como algo perjudicial para éstos. Para ellos, el trabajo es parte de la forma en que el niño se va adaptando a la vida adulta.

b) Las dificultades para el cuidado de los niños, es otro factor importante en el trabajo infantil. Los padres de los menores migrantes no están dispuestos a que sus hijos asistan a la escuela, si no hay una persona de confianza que cuide a sus hijos mientras ellos van a trabajar. El motivo es que toda la familia se integra al trabajo de recolección del ejote y no tienen quien cuide a los escolares durante el tiempo que no están asistiendo a clases. Los jornaleros inician su trabajo a las 7:00 de la mañana y regresan por lo general hasta las 7:00 de la noche. En el caso estudiado los campos de cultivo se localizan, por lo general, lejos de los albergues o campamentos donde las familias duermen. En la actualidad las clases se imparten de 4:00 de la tarde a 8:00 de la noche. Los jornaleros manifiestan que, aún cuando recibieran una compensación para que sus hijos no trabajen, no podrían dejarlos que asistan a clases, ya que tendrían que estar solos desde las 7:00 de la mañana hasta las 4:00 de la tarde, pues no tienen a nadie que los cuide ni les prepare los alimentos.

Los menores de cinco años, que no tienen posibilidad alguna de integrarse a trabajar, son también llevados a los campos de cultivo, pues es la única forma que 
tiene la familia de atenderlos.

c) El aporte de los niños al ingreso familiar, finalmente, el tercer factor trascendental en el trabajo infantil. Entre los jornaleros que migran a Hidalgo el trabajo de los niños de 5 a 14 años contribuye, en promedio, con un $42 \%$ del ingreso de aquellas familias en las que trabajan menores. Por ello, la prohibición absoluta del trabajo infantil para garantizar la asistencia de los niños a la escuela, implicaría una merma considerable de los, ya de por sí, exiguos ingresos de las familias migrantes.

Existe un $35 \%$ de las familias de jornaleros migrantes que no recurren al trabajo infantil. En la mayoría de los casos se trata de grupos familiares que no tienen niños de esa edad, pero se observa un $9 \%$ de familias en las que hay niños de esas edades pero que no se integran a trabajar.

En las familias en las que sólo trabajan mayores de 15 años, el ingreso semanal promedio es de $\$ 311$; mientras que, en las que trabajan menores, el ingreso promedio por ocupado "adulto" es de $\$ 536$. Suponiendo que el trabajo de los niños no sea más que una forma de ayuda a los adultos, ésta se refleja en un incremento considerable (\$225.00) del ingreso por ocupado.

Pero el trabajo infantil no representa sólo una ayuda, dada la naturaleza de la actividad que realizan los jornaleros agrícolas, que consiste en la corta de ejote $y$, dado que la planta es de porte bajo ${ }^{4}$, los niños pueden ser muy productivos. Estimamos que la productividad de un niño equivale al $76 \%$ de la que tendría un adulto.

El aporte del trabajo infantil equivale a un ingreso mensual de $\$ 952$ por niño que trabaja. Este monto es importante, porque sería lo que el Estado debería entregar a las familias en forma de beca para garantizarse que los niños se dedicaran en forma exclusiva a estudiar, garantizando de esta forma su derecho a la educación. Efectos del trabajo infantil

Debido a que la gran mayoría de los estudiantes migratorios trabajan junto con sus padres y hermanos para completar el ingreso del hogar, el tiempo que pueden dedicarse a estudiar es poco y en muchos casos nulo. Los que van a la escuela lo hacen de manera muy irregular y no asisten a todas las clases que se imparten; mucho menos tienen tiempo para dedicarse a hacer tareas, a prepararse para exámenes $\mathrm{y}$, en general, a dedicar el tiempo que comúnmente un estudiante destina al trabajo escolar en su casa. Las niñas son las que, en apariencia, tienen más acceso a la educación, en el caso de Hidalgo el 20\% de las niñas de 5 a 10 años no trabaja en la pizca del ejote y son estudiantes de tiempo completo, mientras que sólo el $11 \%$ de los varones del mismo grupo de edad están en la misma situación.

Esto no se debe a que sus padres se preocupen más por la educación de las mujeres, sino porque cuando éstas tienen hermanos demasiado pequeños para 
trabajar, se deben quedar a cuidarlos en los campamentos y albergues y aprovechan el tiempo para estudiar. Es muy común ver en un salón de clase a varias niñas cargando a sus hermanitos menores.

Cuadro I. Asistencia a la escuela de los menores de 6 a 14 años, según condición de actividad, 2005.

\begin{tabular}{|l|c|c|}
\hline & Número & Porcentaje \\
\hline Sólo trabaja & 69 & 28.16 \\
\hline Estudia y trabaja & 140 & 57.14 \\
\hline Sólo estudia & 24 & 9.80 \\
\hline No trabaja ni estudia & 12 & 4.90 \\
\hline TOTAL & 245 & 100.00 \\
\hline
\end{tabular}

Fuente: Censo sobre características socioeconómicas de las familias de jornaleros migrantes que trabajan en el estado de Hidalgo.

En el caso estudiado, de 245 menores con edades entre 6 y 14 años, sólo 164 $(67 \%)$ asisten a la escuela; de éstos la gran mayoría combina el estudio con el trabajo, lo que dificulta mucho su educación. De acuerdo con los datos obtenidos en esta investigación, el trabajo infantil puede ser un factor que limita la asistencia a la escuela de estos menores, una tercera parte de los niños no va a la escuela y se dedica sólo a trabajar. El trabajo infantil es generalizado, pero los niños se van incorporando a las labores agrícolas de forma paulatina. Si bien empiezan a laborar desde edades muy tempranas, sólo una quinta parte de las niñas y niños de 4 años trabaja; luego los pequeños se van incorporando a las labores agrícolas y cuando cumplen 6 años ya la mayoría (60\%) trabaja. A los 9 años de edad ya $90 \%$ de los niños participa en la corta del ejote y a partir de los 11 años la totalidad de los menores se ha incorporado al trabajo.

La incorporación temprana a las actividades agrícolas es el principal obstáculo para que los niños dispongan del tiempo necesario para asistir a la escuela, estudiar y hacer tareas. Pero también hay niños que no asisten a la escuela y tampoco se dedican a trabajar en el campo. Esto se debe a que son en su mayoría niñas y niños de 6 años que son llevados por sus padres a los campos donde trabajan, pero no participan en la pizca del ejote.

En síntesis, los menores en edad escolar no van a clases, ya sea porque trabajan o porque no hay quien los cuide mientras sus padres y hermanos mayores están en el campo. Ninguna medida para mejorar la educación de los estudiantes migratorios va a tener efecto si no se resuelve este problema.

\section{Marco legal, derechos humanos y trabajo infantil}

El análisis anterior de las condiciones de educabilidad materiales y sus implicaciones en el trabajo infantil, nos da un panorama sobre la situación de los 
jornaleros agrícolas migrantes. Sin embargo, no sólo carecen de las condiciones mínimas, la implicación fundamental es que esto también les impide el ejercicio de sus derechos humanos fundamentales.

Los niños que migran con sus familias para emplearse como jornaleros agrícolas, reciben una educación llena de carencias. En términos de cobertura, permanencia y calidad, los niños jornaleros no logran tener siquiera los servicios educativos que reciben los campesinos en las escuelas multigrado. Una educación pobre para niños pobres. De no hacerse algo pronto, los niños jornaleros migrantes tendrán, cuando sean adultos, tal rezago educativo que los condenará, como a sus padres, a deambular por el país para trabajar como peones con mala paga y vivir en pésimas condiciones, en continua violación a sus derechos humanos.

El trabajo infantil es el principal impedimento para que los menores migrantes mejoren su nivel educativo. El gobierno puede llevar a los campamentos los mejores profesores, el material didáctico más novedoso y modelos educativos que se adapten a las condiciones de los niños migrantes, pero todo esto será en vano si los menores no asisten a la escuela porque tienen que trabajar.

\section{Derechos Humanos de los Jornaleros Agrícolas Migrantes}

De acuerdo con la Ley orgánica de la Comisión Nacional de Derechos Humanos, que tiene su fundamento en la Constitución Política de los Estados Unidos Mexicanos, se entiende por derechos humanos:

... el conjunto de prerrogativas inherentes a la naturaleza de la persona, cuya realización efectiva resulta indispensable para el desarrollo integral del individuo que vive en una sociedad jurídicamente organizada. Estos derechos, establecidos en la Constitución y en las leyes, deben ser reconocidos y garantizados por el Estado.

De esta definición, se desprende la exigencia y obligación ineludible del Estado Mexicano para garantizar las condiciones necesarias para que todos los ciudadanos sujetos de derecho, disfruten y ejerzan las prerrogativas que otorga la Constitución, y que de forma paulatina se superen la desigualdad, la pobreza y la discriminación.

Entre las diversas funciones que tienen la defensa y protección de los Derechos Humanos, destaca para este análisis:

Delimitar, para todas las personas, una esfera de autonomía dentro de la cual puedan actuar libremente, protegidas contra los abusos de autoridades, servidores públicos y de particulares.

De acuerdo con Amartya Sen, uno de los principales problemas de los pobres no es tanto la falta de disponibilidades, que explicaría su miseria si vivieran en sociedades donde prevaleciera una total carencia de recursos, sino la falta de titularidades, esto es, de derechos que les den acceso a parte de la riqueza disponible en la sociedad. El concepto de "titularidad" se refiere a la habilidad de 
las personas para conseguir alimentos $u$ otros bienes a través de los medios legales disponibles. (Sen citado por Boltvinik y Hernández, 2000:40).

El conjunto de titularidades posibles para una persona depende de dos parámetros: su dotación inicial y el 'mapa de titularidades de intercambio con la naturaleza y con otras personas' (que debe ser interpretado en el mismo sentido amplio en que son interpretadas las titularidades, incluyendo, por ejemplo, los derechos adquiridos respecto al Estado). (Boltvinik y Hernández, 2000:40).

No se trata de que el estado mexicano sea tan pobre que no pueda darse el lujo de prescindir del trabajo de una parte de sus niños, sino más bien que hay menores, en este caso los niños jornaleros migrantes, que carecen en la práctica de los derechos humanos que gozan el resto de los infantes.

Si el problema es la falta de derechos, pareciera que la solución consistiría en que se legisle a su favor. Lo grave del caso es que no procede la aprobación de nuevas normas, puesto que esa legislación ya existe.

El artículo 123 Constitucional establece en su apartado "A", Fracción III, con toda claridad, la prohibición de que los menores de 14 años se incorporen a las actividades laborales.

Queda prohibida la utilización del trabajo de los menores de catorce años. Los mayores de esta edad y menores de dieciséis tendrán como jornada máxima la de seis horas. (Constitución Política de los Estados Unidos Mexicanos, Artículo 123, Apartado "A", Fracción III, Fuente: http://info4.juridicas.unam.mx/ijure/fed/9/124.htm?s=).

La ley es clara, pero en la investigación realizada en los campamentos del Valle del Mezquital, Hidalgo, se encontró que 85\% de los niños con edades de 6 a 14 años trabaja. Para más de 200 niños migrantes, sus derechos humanos plasmados en la Constitución se violan a diario, cuando sus familias vienen a trabajar a Hidalgo.

La Ley Federal del Trabajo reglamenta lo dispuesto en el apartado "A" del precepto Constitucional citado, por lo que reitera en su artículo $5^{\circ}$ fracción I, la prohibición expresa para contratar el trabajo de los menores de 14 años, para evitar que su actividad laboral interfiera con su desarrollo físico y mental, así como con la asistencia a la escuela.

Dicha ley permite el trabajo de los menores a partir de los 14 años de edad, y reciben desde entonces una protección a través del establecimiento de condiciones de trabajo especiales, hasta cumplir los 16 años de edad, y los padres, el patrón y el Estado son responsables del cumplimiento de esas normas protectoras.

La citada ley dedica un apartado especial para regular con mayor amplitud el trabajo de los mayores de 14 y menores de 18. En el Título $V$ bis (artículos del 173 
al 180), establece entre otros, el derecho de los menores para que su actividad laboral sea vigilada y protegida de manera especial por la institución denominada "Inspección del Trabajo", cuyas obligaciones y atribuciones se encuentran señaladas de manera expresa en los artículos del 540 al 550 de la misma ley. Entre las funciones que dicha institución podría realizar a favor de los menores que trabajan, estarían: vigilar el cumplimiento de las normas del trabajo; poner en conocimiento de la autoridad las deficiencias y las violaciones a las normas que observe en las empresas o establecimientos (para lo cual pueden realizar visitas a los centros de trabajo en cualquier día y horario, interrogar a trabajadores, patrones o testigos, exigir la presentación de libros, registros o cualquier otro documento que el patrón esté obligado a elaborar y conservar y sugerir la corrección de conductas violatorias de las normas del trabajo).

Como puede observarse, existen leyes que protegen los derechos humanos de menores, pero no se cumplen. Los jornaleros migrantes en el Valle del Mezquital, Hidalgo, nunca han sabido lo que es la visita de un inspector del trabajo. Los menores de 18 no saben que deben trabajar un máximo de 6 horas al día, que tienen derecho a una hora de descanso por cada 3 horas de trabajo, ni que deben de contar con un certificado médico. Los menores de 14 no tienen la menor idea de que cuando sus padres los llevan a trabajar, están violando, no sólo leyes o reglamentos menores, sino incluso preceptos de rango constitucional.

No lo saben y no tienen por qué saberlo. Los responsables de aplicar las leyes son otros; ellos son un grupo social que muestra un sistema legal que no defiende sus derechos humanos consagrados en la Constitución.

Además de que viola la legislación nacional, el trabajo infantil lleva al incumplimiento de tratados internacionales ratificados por México. El trabajo de niños de hasta 6 años contraviene lo dispuesto en la Declaración de los Derechos del Niño, proclamada por la Organización de las Naciones Unidas en noviembre de 1959.

\section{Declaración de los Derechos del Niño \\ Proclamada por la Asamblea General de las Naciones Unidas en la resolución 1386 (XIV), de 20 de noviembre de 1959 Principio 9.}

"No deberá permitirse al niño trabajar antes de una edad mínima adecuada; en ningún caso se le dedicará ni se le permitirá que se dedique a ocupación o empleo alguno que pueda perjudicar su salud o su educación o impedir su desarrollo físico, mental o moral".

Fuente: http://www.unhchr.ch/spanish/html/menu3/b/25_sp.htm

Aunque hay varios instrumentos de derecho internacional que tienen que ver con el trabajo infantil ${ }^{5}$, consideramos como demostrado que cuando los niños 
jornaleros realizan labores que interrumpen su educación, se produce un claro desacato de la legislación nacional e internacional, por lo que sería ocioso continuar citando leyes y tratados que se atropellan ${ }^{6}$.

Por su importancia y vigencia mencionaremos sólo uno más: la situación encontrada en los campamentos de migrantes, revela que en este caso específico se incumple con lo dispuesto en la Convención de los Derechos del Niño, en especial en su artículo 32, en el que los estados firmantes se comprometen a proteger a los niños contra el desempeño de cualquier trabajo que pueda entorpecer su educación y a establecer sanciones para garantizar la aplicación efectiva de estas disposiciones.

Las leyes y tratados aquí citados, no han sido llevados a cabal práctica en el caso que nos ocupa. De la omisión por parte del estado, se han violentado los llamados derechos humanos de segunda generación ${ }^{7}$ de los jornaleros agrícolas migrantes, a saber:

Toda persona tiene derecho a la seguridad social y a obtener la satisfacción de los derechos económicos, sociales y culturales.

Toda persona tiene derecho al trabajo en condiciones equitativas y satisfactorias.

Toda persona tiene derecho a formar sindicatos para la defensa de sus intereses.

Toda persona tiene derecho a un nivel de vida adecuado que le asegure a ella y a su familia la salud, alimentación, vestido, vivienda, asistencia médica y los servicios sociales necesarios.

Toda persona tiene derecho a la salud física y mental.

Durante la maternidad y la infancia toda persona tiene derecho a cuidados y asistencia especiales.

Toda persona tiene derecho a la educación en sus diversas modalidades.

La educación primaria y secundaria es obligatoria y gratuita.

Fuente: Página Web: http://www.cndh.gob.mx

Para nuestro análisis destacan los derechos humanos de segunda generación, pues en ellos se reconocen los derechos humanos indispensables para procurarse una vida digna, una vida de oportunidades materiales, sociales y culturales que a su vez permita el ejercicio de los derechos y obligaciones en una sociedad; en el universo de la muestra, observamos claramente que los derechos y la satisfacción de condiciones materiales, laborales, de salud (física y mental), así como de educación, no se cumplen, por el contrario, a pesar de la existencia de normas jurídicas, los jornaleros agrícolas migrantes, no tienen acceso a condiciones mínimas satisfactorias que les permitan condiciones de vida dignas, violando con ello, sus derechos humanos fundamentales. 
La agravante, es que los JAM pertenecen a los llamados grupos vulnerables, es decir:

... grupos o comunidades que, por circunstancias de pobreza, origen étnico, estado de salud, edad, género o discapacidad, se encuentran en una situación de mayor indefensión para hacer frente a los problemas que plantea la vida y no cuentan con los recursos necesarios para satisfacer sus necesidades básicas. La vulnerabilidad coloca a quien la padece en una situación de desventaja en el ejercicio pleno de sus derechos y libertades.

La vulnerabilidad, de acuerdo con la propia CNDH

fracciona y, por lo tanto, anula el conjunto de garantías y libertades fundamentales, de tal forma que las personas, grupos y comunidades en esta situación tienen derechos únicamente a nivel formal, ya que en los hechos no se dan las condiciones necesarias para su ejercicio... Esta circunstancia viola los derechos de los miembros más débiles de la sociedad y los margina, razón por la cual el Estado tiene la responsabilidad de proteger a estas personas, quienes frecuentemente desconocen cuáles son sus derechos, ignoran los medios para hacerlos valer y carecen de los recursos necesarios para acudir ante los sistemas de justicia.

Los JAM, son un grupo social vulnerable, porque se encuentran en franca desigualdad con respecto a otros grupos, sus precarias condiciones materiales, los hace incapaces de satisfacer sus necesidades básicas, son marginados y por su condición de migrantes, no pueden acceder a los servicios públicos que ofrece el estado.

Pareciera que lo que se necesita no es promulgar nuevas leyes, sino que se respeten las que ya existen. Los niños migrantes están viviendo lo que O'Donnell llama la ciudadanía limitada o de baja intensidad.

En nuestros países casi todos somos ciudadanos en términos de derechos políticos, pero muchos no gozan de derechos civiles básicos ni, por supuesto, sociales. Las víctimas de esa ciudadanía no sólo son pobres materialmente, también lo son legalmente (O'Donnell, 2005: 26).

En el caso de los migrantes jornaleros agrícolas se da lo que O'Donnell califica como las "zonas marrones", esto es, que hay zonas geográficas o sectores sociales en los que la legalidad del Estado no se aplica.

De hecho, muchos de nuestros países tienen un régimen democrático que coexiste con una legalidad intermitente y sesgada. Simplemente la legalidad del Estado no se extiende a vastas regiones de no pocos de nuestros países (...) aún en regiones donde el sistema legal tiene alcance, éste es aplicado no pocas veces con sesgos discriminatorios 
contra varias minorías y aún mayorías, tales como las mujeres y los pobres (O'Donnell, 2004:49).

De lo que se trata entonces es de ampliar la ciudadanía a estos sectores hoy excluidos, para el pleno ejercicio de los derechos humanos es indispensable el acceso a la educación básica, puesto que será lo que les permita, cuando sean adultos, tener la libertad de decidir. En su célebre ensayo "ciudadanía y clase social", T.H. Marshall expone el pensamiento del economista británico Alfred Marshall, con el cual coincide.

(...) sostenía que el Estado debía imponer de alguna forma su capacidad $\begin{array}{lllllllllll}c & 0 & e & r & c & i & t & i & v & a\end{array}$ por ejemplo, obligando a los niños a asistir a la escuela, porque los que no han recibido educación no pueden apreciar, y por tanto no pueden elegir libremente, las cosas buenas que distinguen la vida de los caballeros de la vida de la clase trabajadora. Se trata de obligarlos y ayudarlos a subir el primer peldaño; de ayudarlos, si ellos quieren, a subir muchos más. Nótese que sólo se les obliga en el primer peldaño. La libre elección se produce en cuanto han adquirido la capacidad de elegir (Marshall, 1998:19).

En el caso de los migrantes existe la idea errónea, entre los propios padres, de que los niños no van a la escuela porque no quieren, como si se tratara de un acto opcional. Muchos coincidimos con ambos Marshall que es función del Estado velar porque los niños asistan a la escuela y obligar a los padres, mediante sanciones, si fuera preciso, para que los dejen ir. Sólo cuando se tiene acceso a un mínimo de instrucción inicial se estará en condiciones de elegir con libertad, de ejercer con conciencia los derechos humanos que todas las personas tienen garantizados en

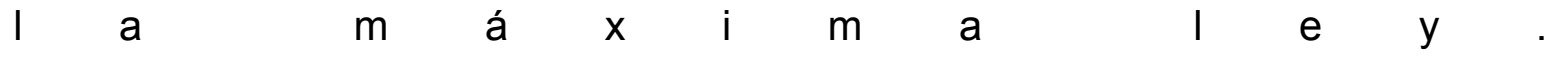
Pero ¿cómo usar el poder coercitivo del Estado en este caso? En Hidalgo la violación fragante a toda la legislación vigente en materia de protección a la infancia no la hacen grandes empresas que contraten mano de obra de manera ilegal. No se trata tampoco, como se cree en forma errónea, que existan crueles "enganchadores" que explotan sin misericordia a mujeres y niños para multiplicar sus ganancias (Román, 2005:36). En el caso que estudiamos son los propios padres los que incorporan a sus hijos en las actividades productivas, como parte de las estrategias de sobrevivencia que adoptan las familias. No se puede, en este caso, enviar a inspectores del trabajo u obligar a los padres, por medio de acciones policíacas a que cumplan la ley.

Desde una posición radical se diría que la ley no se discute, sólo se aplica "dura lex, sed lex"8. Pero en este caso la situación es muy compleja. Por ejemplo, el cabal acatamiento de la norma constitucional que prohíbe el trabajo de los menores de 14 años sería demasiado oneroso para las familias de migrantes, en 
las cuales el $40 \%$ del ingreso familiar es aportado por estos menores. Los jornaleros migrantes violan la ley cuando llevan a sus hijos a la pizca del ejote, en lugar de enviarlos a la escuela, pero no lo hacen por un afán delictivo sino por necesidad.

Se nos acaban las opciones. Hemos dicho que la ausencia de derechos de los niños migrantes no se resuelve mediante la promulgación de leyes, pues éstas ya existen.

Hemos dicho, también, que no se puede obligar a los jornaleros a que cumplan con las leyes, puesto que éstas se incumplen por necesidad y no por capricho, por lo que el acatamiento de la norma podría significar una fuerte merma de los ingresos, que pondría en peligro la sobrevivencia de las familias. ¿Qué procede entonces?

Diversos autores se han pronunciado por buscar formas creativas en las que el gobierno pueda promover el ejercicio efectivo de los derechos humanos de los niños migrantes, reconociendo las desfavorables situaciones que los rodean y los convierten en entes vulnerables. Un asunto de gran importancia es que los niños tienen que emigrar con la familia en busca de una mejor calidad de vida, lo cual repercute en su desarrollo personal, porque al momento de migrar abandonan sus estudios para dedicarse a contribuir al sustento económico para la familia (Cohen, 2000).

En la actualidad existen buenas condiciones institucionales para promover la integración de los migrantes a la escuela. En la "ley para la protección de los derechos de niñas, niños y adolescentes", vigente desde 2000, se crean restricciones para la discriminación en materia de oportunidades educativas y se establece la obligación del gobierno para establecer los mecanismos que sean necesarios, para contrarrestar las causas culturales o socioeconómicas que propicien dicha discriminación, como es el caso de los niños y niñas jornaleros agrícolas.

En síntesis, las normas jurídicas no pueden ni deben hacer excepción alguna para exentar de su cumplimiento a ciertos sectores de la población. Por ejemplo, la norma constitucional que regula el trabajo infantil no puede reformarse para que diga que se prohíbe el trabajo de los menores de 14 años, excepto cuando su trabajo sea indispensable para el mantenimiento de la familia. No es viable entonces plantear que las leyes existentes se adapten a la realidad socioeconómica, lo que hay que hacer es que la ley se cumpla. No obstante, hemos dicho también que no es posible usar medidas coercitivas para obligar a los jornaleros migrantes a cumplir las leyes, puesto que no cuentan con las condiciones mínimas para hacerlo. Por tanto, la única opción viable es que el Estado instrumente medidas para ayudar a los migrantes a contar con las condiciones socioeconómicas indispensables, para que les pueda ser demandado 
el respeto de las normas, lo cual, a nuestro juicio, se lograría mediante buena coordinación de la política educativa con la política social.

\section{Reflexión final}

Como ha quedado señalado, la vida de los jornaleros agrícolas migrantes en el Valle del Mezquital, Hidalgo, está rodeada de difíciles condiciones de educabilidad materiales, que históricamente no les ha permitido ejercer el conjunto de derechos humanos que garantizan las leyes mexicanas.

Especial preocupación merecen las causas de la situación de los niños y niñas indígenas migrantes, como es la práctica del trabajo infantil entre la niñez que migra con su familia como respuesta a la pobreza y la extrema pobreza de sus lugares de origen, que sin duda dificultan el acceso, la permanencia y conclusión del ciclo escolar.

Los derechos de los niños migrantes, como el derecho de toda persona al disfrute del mayor nivel posible de salud física y mental, el derecho a la educación, el derecho de igualdad ${ }^{9}$, se encuentran en permanente transgresión, pues aunque las leyes consagran y protegen estos derechos, el estado Mexicano no ha logrado políticas sociales eficaces para revertir los efectos de la desigualdad, inequidad y exclusión social en la que viven muchos y diversos grupos sociales en nuestro país.

Como ha sido reconocido y documentado en el informe del Relator Especial, de la ONU, sobre los derechos y las libertades fundamentales de los indígenas Rodolfo Stavenhagen:

La educación es un instrumento indispensable para que la humanidad pueda progresar hacia los ideales de paz, libertad y justicia social, que está al servicio de un desarrollo humano más armonioso, más genuino, para hacer retroceder la pobreza, la exclusión, las incomprensiones, las opresiones y las guerras. El derecho a la educación se revela clave para millones de indígenas en todo el mundo no sólo como un medio para salir de la exclusión y la discriminación que han sufrido históricamente sino también para el disfrute, mantenimiento y respeto de sus culturas, idiomas, tradiciones y conocimientos.

El derecho a la educación es reconocido en numerosos instrumentos internacionales, entre ellos, la Declaración Universal de los Derechos Humanos y los dos Pactos Internacionales de Derechos Humanos, la Convención sobre la Eliminación de todas las Formas de Discriminación Racial, la Convención relativa a la lucha contra las discriminaciones en la esfera de la Educación y el Convenio 169 de la OIT sobre pueblos indígenas y tribales en países independientes.

Es indispensable señalar la importancia del derecho a la educación, pues si bien ésta no es determinante para superar los problemas estructurales de la pobreza en América Latina, como la desigualdad, la inequidad y la exclusión cultural, social 
y política; sí condiciona el disfrute total de los demás derechos humanos, entre otros, el derecho personal a ser reconocido como miembro de una comunidad lingüística; al uso de la lengua en privado y en público; al uso del propio nombre; así como los derechos colectivos de los grupos lingüísticos a la enseñanza de la propia lengua y cultura. Éstos y otros derechos son cruciales para el disfrute completo del derecho a la educación de los pueblos indígenas así como de los jornaleros agrícolas migrantes.

Los factores que dificultan el acceso de los jornaleros agrícolas migrantes, en su mayoría indígenas, a la educación, son principalmente la discriminación y falta de acceso en condiciones de igualdad, en comparación con otros sectores sociales.

Pensar que estos niños puedan asistir con regularidad y completar la escuela primaria, en el Valle del Mezquital, está aún lejos de lograrse. Esto se debe, principalmente a la ausencia de políticas integrales que resuelvan el gran problema del trabajo infantil. La pobreza y la deficiente nutrición de los niños migrantes, constituyen otro factor que con frecuencia limita su asistencia a la escuela. Es indispensable la intervención rápida y eficaz para poder asegurar el disfrute de tal derecho.

Debido a lo anterior, la forma más directa para que los niños migrantes rompan con el círculo vicioso de la pobreza es que mejoren su nivel educativo. Para ello se debe garantizar que asistan a la escuela y permanezcan en ella el tiempo que el programa establece. Además se debe contar con un programa social que compense a las familias por los ingresos que dejarán de obtener, al disminuir o eliminar el trabajo infantil y un esquema de atención educativa que contemple el cuidado de los niños y su alimentación.

La iniciativa de SEDESOL de poner en marcha el Programa Monarca en el estado de Hidalgo, es una excelente oportunidad para mejorar la permanencia de niñas y niños migrantes en el sistema educativo, ya que se trata de un programa diseñado de manera especial para atender las necesidades de esta población. Si bien los montos contemplados para becas son insuficientes para eliminar por completo el trabajo infantil, pueden provocar una disminución significativa del mismo, con el consecuente incremento de la asistencia a clases, así como del tiempo para estudiar y realizar labores escolares, lo que sin duda ayudará a mejorar el aprovechamiento escolar y a darles a los niños migrantes mayores oportunidades de superar, en el futuro, las precarias condiciones que han vivido en la niñez.

Es claro que, mientras el Estado mexicano no garantice el pleno ejercicio de los derechos humanos de los JAM, éstos no podrán aprovechar las oportunidades educativas y por lo tanto, se corre el peligro de continuar reproduciendo las condiciones materiales de este grupo social.

\section{NOTAS}

${ }^{1}$ Este artículo es resultado del trabajo de investigación denominado "Situación 
socioeconómica, cultural y educativa de niños que pertenecen a familias de jornaleros agrícolas en el Estado de Hidalgo", llevado a cabo por un grupo de profesores investigadores, adscritos al Área Académica de Ciencias de la Educación, de la Universidad Autónoma del Estado de Hidalgo, durante los años 2005 y 2006 en la zona del Valle del Mezquital, Hidalgo, financiado por el Fondo sectorial SEP-SEBYN-CONACYT 2004, y coordinado por el Dr. Carlos Rafael Rodríguez Solera, profesor investigador en la misma Universidad.

${ }^{2}$ No olvidemos la importancia del respeto efectivo a los derechos humanos, fundamental en un estado democrático y que, actualmente constituye un tema de agenda internacional como una tendencia mundial paralela a los nuevos modelos políticos globalizados de economía del conocimiento.

${ }^{3}$ Besserer (1999), proporciona un breve panorama sobre el desarrollo de esta categoría.

${ }^{4}$ Los ejotes son la vaina del frijol (Phaseolus vulgaris) en su etapa tierna.

${ }^{5}$ Los más importantes son La Declaración Universal de los Derechos Humanos, ratificada por México en 1948, que establece la educación como un derecho básico de todas las personas y el Convenio 169 de los Derechos de los Pueblos Indígenas y Tribales en Países Independientes, promovido por la Organización Internacional del Trabajo (OIT) y ratificado por México en 1990.

${ }^{6}$ Para los interesados en el tema existe una amplia bibliografía. Uno de los trabajos más completos sobre el tema de legislación infantil lo constituye el " $\mathrm{V}$ informe sobre los derechos y la situación de la niñez en México, avances y retrocesos: balance de una década", publicado por el Colectivo Mexicano de Apoyo a la Niñez (2000), en el que se hace un amplio análisis de la situación jurídica de los niños mexicanos en distintos contextos. Laura Salinas (2000) hace un trabajo sobre la tutela de los derechos humanos de las mujeres y menores en las normas jurídicas mexicanas. En su trabajo sobre infancia y legislación, Robert Cohen (2000) propone, por su parte, la promulgación de leyes mexicanas acordes con la Convención sobre los Derechos de la Niñez. Otros trabajos que pueden ser de interés son; Villoro, 2002; Pujol y Torres, 2000; UNICEF, 2003; Corona y Fernández, 2000; García y Salazar, 1999; Rabanales, 2000; Barreiro, 2000.

7 Para el análisis de los derechos humanos, desde la perspectiva histórica se considera la existencia de 3 generaciones de derechos, de acuerdo al orden cronológico de aparición o reconocimiento del orden jurídico de cada Estado. Los de primera generación aluden a los derechos civiles y políticos, también denominados libertades clásicas, entre ellos se encuentran: universalidad de las libertades independientemente de raza, color, idioma, posición social o económica; el derecho a la vida, a la libertad, a la seguridad jurídica; igualdad de género; integridad física y emocional; legalidad de las acciones judiciales; libre tránsito, derecho a la nacionalidad, entre otros. Los de segunda generación, se refiere a los 
derechos económicos, sociales y culturales, debido a los cuales, el Estado de Derecho pasa a una etapa superior, es decir, a un Estado Social de Derecho. Se demanda un Estado de Bienestar que implemente acciones, programas y estrategias, a fin de lograr que las personas los gocen de manera efectiva. Finalmente, los de tercera generación que se refieren a '...incentivar el progreso social y elevar el nivel de vida de todos los pueblos, en un marco de respeto y colaboración mutua entre las distintas naciones de la comunidad internacional. Destacan: la autodeterminación de los pueblos, independencia económica y política, identidad nacional y cultural, la paz, la cooperación internacional y regional', entre otros (http://www.cndh.gob.mx).

${ }^{8}$ La ley es dura, pero es la ley.

9 Siendo el derecho a la educación universalmente reconocido, los pueblos indígenas aún no lo disfrutan en su plenitud. El grado de analfabetismo, de bajos niveles educativos y de baja asistencia a centros escolares, sobre todo a nivel medio y superior, tiende a ser más elevado entre los pueblos indígenas que en el resto de la población.

\section{FUENTES DE CONSULTA}

ALCALÁ, Elio y Teófilo Coutier. 1994. Migrantes Mixtecos. El proceso migratorio de la Mixteca Baja. INAH. México.

Arroyo, Ramiro. 1998. "Los jornaleros agrícolas migrantes una visión nacional". En: Memoria del Foro Sobre Jornaleros, Agrícolas Migrantes. INI. México.

Barreiro García, Norma (2000) El trabajo infantil, un concepto de difícil consenso. En: Del Río Lugo, Norma (coordinadora). La infancia vulnerable de México en un mundo globalizado, UAM-UNICEF, México, 2000. Versión electrónica: http://www.uam.mx/cdi/index.html,

Bello, Manuel. Escuela y condiciones de educabilidad. Ponencia presentada al Congreso Internacional "Reformas y Escuelas para el Nuevo Siglo", organizado por Foro Educativo y REDUC. Lima, 7 al 10 de Octubre de 2003. Versión digital en: http://www.foroeducativo.org.pe/congreso/Escuela-y-Educabilidad.doc

Boltvinik, Julio y Enrique Hernández Laos. 2000. Pobreza y distribución del ingreso en México. Siglo XXI Editores, México.

Bourdieu, Pierre. 1987. Los tres estados del capital cultural. Sociológica, vol. 2, n5, México, otoño.

Bourdieu, Pierre; Passeron, Jean Claude. 1970. La reproducción. Elementos para una teoría del sistema de enseñanza. Editorial Laia, Barcelona, Branz-Spall, Angela and Al Wright. 2004. A History of Advocacy for Migrant Children and Their Families: More than 30 Years in the Fields. Educational Resources Infomation Center (ERIC), U.S. Departament of Education. ED 481 635, RC024212.

Besserer, Federico (1999) "Estudios trasnacionales y ciudadanía transnacional" 
En: Gail Mummert (Ed), Fronteras Fragmentadas. México: Colegio de MichoacánCIDEM, pp. 215-238.

CEPAL (Comisión Económica para América Latina y el Caribe). Globalización y desarrollo. CEPAL, Brasilia, 2002. Versión electrónica:

http://www.eclac.cl/publicaciones/SecretariaEjecutiva/3/LCG2157SES293/Globac10.pdf

Cohen, Robert (2000) Infancia y legislación. Hacia leyes mexicanas acordes con la Convención sobre los Derechos de la Niñez. En: Corona Caraveo, Yolanda (coordinadora), Infancia, legislación y política, UAM-UNICEF, México, 2000. Versión electrónica: http://www.uam.mx/cdi/index,html

Colectivo Mexicano de Apoyo a la Niñez. $V$ informe sobre los derechos y la situación de la niñez en México, avances y retrocesos: balance de una década. México, 2000.

Ezpeleta, Justa y Eduardo Weiss. 2002. Cambiar la escuela rural. Evaluación cualitativa del Programa para Abatir el Rezago Educativo. DIE-CINVESTAV. México.

Gajardo, Marcela y Ana María de Andraca. 1988. Trabajo infantil y escuela. Las zonas rurales. FLACSO, Santiago.

Galindo, Claudia. 1994. Los jornaleros agrícolas del Estado de Oaxaca: análisis sobre las causas y condiciones de la migración en este grupo social y las políticas de acción institucional. (Tesis). UNAM- Facultad de Ciencias Políticas y Sociales. México.

García Méndez, Emilio y María Cristina Salazar (comp.) 1999. Nuevas perspectivas para erradicar el trabajo infantil en América Latina. Seminario regional post- Oslo. UNICEF, Tercer Mundo Editores, Colombia.

Gómez, María. "Sobre la naturaleza del derecho indígena. Reconocimientos constitucional y legales". En: Análisis de la situación de los niños indígenas y niños jornaleros agrícolas. Primer Foro Regional. COMEXANI-UPN. México. 1994. Pp. 67-93

Goodman, Walter. "New Harvest, Old Shame, About Farm Workers. New York Times", April 17, 1990. Versión electrónica en: http://query.nytimes.com/gst/fullpage.html?res=9C0CE0DE173EF934A25757C0A9 66958260

Guerra, María. 1994. "Seguridad social y condiciones de trabajo de los niños jornaleros agrícolas en Sinaloa”. En: Análisis de la situación de los niños jornaleros agrícolas. Primer Foro Regional. UPN-COMEXANI. México.

Guerrero Verano, Martha Guadalupe, 2000. "Los Derechos Humanos de los Refugiados Guatemaltecos en México", Tesis de Licenciatura, UNAM.

López, Néstor y Juan Carlos Tedesco. Las condiciones de la educabilidad de los niños y adolescentes en América Latina. (Documento para discusión, versión 
preliminar), Instituto Internacional de Planeamiento de la Educación. Buenos Aires, 2002. Versión digital en: http://www.iipe-buenosaires.org.ar/pdfs/educabilidad.PDF Lunon, Janis K. 1988. Migrant Student Record Transfer System: What Is It and Who Uses It? ERIC Clearinghouse on Rural Education and Small Schools, Las Cruces, New Mexico. Office of Educational Research and Improvement (ED), Washington, DC. U.S.; Arkansas.

Marshall, T.H. 1987. Ciudadanía y clase social. Alianza Editorial, Madrid, 1998. Medina, Andrés, "La frontera sur y los procesos étnicos". México indígena, Vol.III.núm.14, México, INI.

Moreno Barrera, Francisco Javier. 2005. "La inversión pública en el programa educación primaria para niñas y niños migrantes". En: Memoria del Foro la Educación de Menores Jornaleros Migrantes en el Valle del Mezquital, Hidalgo.Voces de los Jornaleros Migrantes. Pachuca, Hidalgo.

Navarro, Luis. La noción de condiciones de educabilidad como expresión de la demanda por un mínimo de equidad social para la educación. Notas para una discusión.

Proyecto "Equidad Social y Educación en los Países Andinos y el Cono Sur", Oficina

Regional del Instituto Internacional de Planificación de la Educación (IIPE) de UNESCO en Buenos Aires, Julio 2003. Versión digital en: http://www.foroeducativo.org.pe/congreso/Educabilidad-equidad.doc

O'Donnell, Guillermo. 2004. "Notas sobre la democracia en América Latina". En: La democracia en América Latina. Hacia una democracia de ciudadanas y ciudadanos. El debate conceptual sobre la democracia. Programa de Naciones Unidas para el

Desarrollo, Perú.

2005. Democracia y estado de derecho. Nexos, № 325 , enero.

PAJA, 2005. (Programa de Atención a Jornaleros Agrícolas). Reglas de operación del programa.

PRIES, Ludger. 2002. "Migración transnacional y la perforación de los contenedores de Estadosnación". En: Estudios Demográficos y Urbanos, México: El Colegio de México, Vol. 17, Núm. 3, S. 571-597.

Pujol Rosas, Rebeca F. y Eduardo Torres Maldonado. Vigencia y eficacia de los derechos de los niños y niñas en México y los impactos de la globalización. En: Corona Caraveo, Yolanda (coord.), Infancia, legislación y política. UAM-UNICEF, México, 2000. Versión electrónica: http://www.uam.mx/cdi/index,html

Rabanales García, Marvin. El sentido real de la Convención sobre los Derechos de la Niñez. La educación y su papel como motor de cambio. En: Corona Caraveo, Yolanda (coordinadora). Infancia, legislación y política. UAM-UNICEF, México, 2000. Versión electrónica: http://www.uam.mx/cdi/index.html 
Raesfeld, Lydia. 2003. "Educación y sociedad. México: una sociedad multicultural". En: AMPO (ed.) La orientación educativa como eje del desarrollo integral en un mundo cambiante, Memoria del 5to Congreso Nacional de Orientación Educativa, Puebla.

Ramírez, Marcela. 2001. "Situación de vulnerabilidad de las niñas y los niños

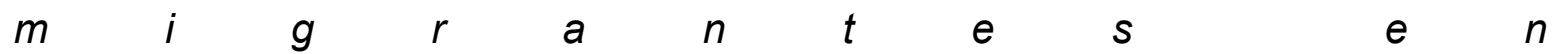
México. Problemática para su acceso a una educación de calidad". En: Norma del Río (Coord.). La infancia vulnerable de México en un Mundo Globalizado. UAMUNICEF. México.

Rockwell, Elsie y R. Mercado. 1999. La escuela, lugar del trabajo docente: descripciones y debates. México: Departamento de Investigaciones Educativas, CINVESTAV-IPN. 1986, Reeditado por SEP, México, D.F.

1986. De huellas, bardas y veredas. Departamento de Investigación EducativaDIE. México.

Latina, 1985. Os modelos teóricos e realidade social, Sao Paulo: Cortez Editora Editora Autores Asociados. Pp. 151-172. (Reproducido como Documento DIE), México.

Rodríguez Pérez, Beatriz E y Víctor A. Corrales. 2000. Los hijos e hijas de jornaleros agrícolas en Sinaloa. Diagnóstico sobre el trabajo infantil y su contexto. Secretaría de Planeación y Desarrollo, México.

Rojas Rangel, Teresa (Coord.). 2004. Evaluación del programa de educación primaria para niñas y niños migrantes. UPN, México, D.F.

La falta de equidad en la educación primaria de la población infantil jornalera migrante (PIJM): Sinaloa, un estudio de caso. Foro Invisibilidad y conciencia: Migración interna de niñas y niños jornaleros agrícolas en México 26 y 27 de septiembre del 2002 http://www.uam.mx/cdi/foroinvisibilidad/index.html

Sánchez Saldaña, Kim. 1996. Migración de la montaña de Guerrero: el caso de jornaleros estacionarios en Tenextepango, Morelos. Escuela Nacional de Antropología e Historia. México.

Schemelkes, Sylvia, "Visibilizar para crear conciencia. Los Jornaleros Agrícolas de México a la luz de los Derechos Humanos", Foro Invisibilidad y conciencia: Migración interna de niñas y niños jornaleros agrícolas en México, 26 y 27 septiembre, 2002.

SEDESOL (Secretaría de Desarrollo Social). Medición de la pobreza 2002-2004. En:

www.sedesol.gob.mx/prensa/comunicados/presentaciones/Mediciondelapobreza2 002- 2004.ppt

SEP (Secretaría de Educación Pública). Reglas de Operación del Programa de Educación Primaria para Niñas y Niños Migrantes, 2006. SEP, México, D.F., 23 de febrero de 2006. Versión electrónica: 
http://www.ordenjuridico.gob.mx/Federal/PE/APF/APC/SEP/Reglas/2006/2302200 6(3).pdf

SEP (Secretaría de Educación Pública). Reglas de Operación para el Programa Educación Primaria para Niñas y Niños Migrantes 2002. SEP, SEByN-DGIE. Diario Oficial de la Federación. Órgano del Gobierno Constitucional de los Estados Unidos Mexicanos. SEGOB. Talleres Gráficos de México. México. 13 de marzo del 2002.

Tedesco, Juan Carlos. "Opinión en torno a resiliencia y educabilidad: un comentario interesante. Educar en medio de la tormenta". Revista Clarín. Año VII, número 2528, marzo de 2003a. Versión digital en: http://www.resiliencia.cl/actuali/. 2003. Educar, en la sociedad del conocimiento. Fondo de Cultura Económica. Buenos Aires,

Téllez Jiménez, Elizabeth. 2006. Desigualdad social y pobreza de alumnos de escuela primaria, Tesis para optar al grado de Doctora en Ciencias de la Educación. Universidad Autónoma del Estado de Hidalgo. Pachuca, Hidalgo.

UNICEF (United Nations Children's Fund). 2003. Informe anual. UNICEF, México. Villa Acevedo, María Virginia (Coord). 2005. Expectativas de los padres de los niños jornaleros agrícolas migrantes respecto a la educación primaria. Secretaría de Educación Pública, México.

Villoro, Luis. 2002. Los derechos indígenas. Como derechos primordiales en los estados latinoamericanos modernos. México Indígena, vol.000. 